\title{
The Electrical Properties of Some Composite Materials Based on Sodium and Tantalum Oxides
}

\author{
D. Malaescu ${ }^{a}$, I. Grozescu ${ }^{a, b}$, P. Sfirloaga ${ }^{b}$, P. Vlazan ${ }^{b}$ And C.N. Marin ${ }^{c *}$ \\ a"Politehnica" University, Victoriei No. 2, RO-300006 Timisoara, Romania \\ ${ }^{b}$ National Institute for Research and Development in Electrochemistry and Condensed Matter, \\ Plautius Andronescu No. 1, RO-300224 Timisoara, Romania \\ ${ }^{c}$ West University of Timisoara, Faculty of Physics, Bd. V. Parvan no. 4, 300223 Timisoara, Romania \\ (Received March 30, 2015; revised version August 20, 2015; in final form September 28, 2015)
}

Two samples of $\mathrm{Na}$-Ta oxides were synthesized by the hydrothermal method at reaction temperatures of $160^{\circ} \mathrm{C}$ (sample A) and $200^{\circ} \mathrm{C}$ (sample B). For reference, a third sample of pure $\mathrm{NaTaO}_{3}$ was prepared by the sol-gel method (sample C). Using X-ray diffraction, scanning electron microscopy, UV-vis diffuse reflectance spectra and electric measurements, structural, morphologic, spectroscopic and electric properties of samples were investigated. The structural characterization by X-ray diffraction revealed that samples A and B are mixtures of Na-Ta oxides (including $\mathrm{NaTaO}_{3}$ and other compounds), whilst sample $\mathrm{C}$ is pure $\mathrm{NaTaO}_{3}$. UV-vis diffuse reflectance spectra allowed evaluation of the band gap energy $\left(E_{\mathrm{g}}\right)$, resulting in $3.88 \mathrm{eV}$ for sample $\mathrm{A}, 3.93 \mathrm{eV}$ for sample $\mathrm{B}$ and $4.1 \mathrm{eV}$ for sample C. Electrical resistivity measurements, over the temperature range $300-450 \mathrm{~K}$, showed a typical semiconductor behavior of the investigated samples, with the effective activation energy, $E_{\mathrm{a}}$ of $0.47 \mathrm{eV}$ (sample A), $0.45 \mathrm{eV}$ (sample B) and $0.82 \mathrm{eV}$ (sample $\mathrm{C}$ ). Based on the Mott variable range hopping model, the conductivity mechanism in the investigated samples was analyzed. The results shown that the density of states at the Fermi-level, $N\left(E_{\mathrm{F}}\right)$ is constant in the investigated temperature range and the typical values of $N\left(E_{\mathrm{F}}\right)$ are $0.713 \times 10^{18} \mathrm{eV}^{-1} \mathrm{~cm}^{-3}$ (sample A), $0.621 \times 10^{18} \mathrm{eV}^{-1} \mathrm{~cm}^{-3}$ (sample B) and $0.855 \times 10^{17} \mathrm{eV}^{-1} \mathrm{~cm}^{-3}$ (sample C). Other parameters of VRH model such as the hopping distance $R$ and the hopping energy $W$ have also been computed and the following values at the room temperature were obtained: $R=15.7 \mathrm{~nm}$ and $W=86 \mathrm{meV}$ (for sample A); $R=16.3 \mathrm{~nm}$ and $W=89 \mathrm{meV}$ (for sample B) and $R=26.7 \mathrm{~nm}$ and $W=147 \mathrm{meV}$ (for sample C).

DOI: $10.12693 /$ APhysPolA.129.133

PACS: 81.20.Ev, 81.20.Fw, 72.20.Ee, 72.80.Tm

\section{Introduction}

$\mathrm{NaTaO}_{3}$ is a typical perovskite oxide and has many applications in UV-detection [1], gas sensors [2], nanoelectronics and electroceramic memories [3]. Recent researches showed that the $\mathrm{NaTaO}_{3}$ composite ceramics can be used as a new thermoelectric material for energy generation $[4,5]$, or as a promising photocatalyst [6].

To prepare $\mathrm{NaTaO}_{3}$ powder, solid state synthesis method may be used [7], but it requires high temperatures and long calcination time. Recently, other methods have been used to synthesize $\mathrm{NaTaO}_{3}$ powder such as solgel [8], alkalide reduction method [9], and solvothermal method [10].

The present paper is a natural step further in finding new materials. In this respect we obtained and characterized new composite materials based on $\mathrm{NaTaO}_{3}$ and other sodium and tantalum oxides, that may result from the obtaining reaction, aiming to compare their electrical properties with those of $\mathrm{NaTaO}_{3}$.

Two powder samples of $\mathrm{Na}$ - Ta oxide composite materials were synthesized by the hydrothermal method at the reaction temperatures of $160^{\circ} \mathrm{C}$ (sample A) and $200^{\circ} \mathrm{C}$

*corresponding author; e-mail: cmarin@physics.uvt.ro (sample B). For reference, a third sample of pure $\mathrm{NaTaO}_{3}$ was prepared by the sol-gel method (sample C).

Based on the X-ray diffraction (XRD), scanning electron microscopy (SEM), UV-vis spectra and electric resistivity measurements over the temperature range from $30^{\circ} \mathrm{C}$ to $175^{\circ} \mathrm{C}$, the morpho-structural, photocatalytic and electrical properties of samples were investigated. From the electrical measurements of resistivity, the effective activation energy, $E_{\mathrm{a}}$ of samples was determined and the static conductivity mechanism in the samples was explained using Mott's variable range hopping (VRH) model.

\section{Obtaining and characterization of samples}

Two samples of Na-Ta oxide composite were synthesized by the hydrothermal method. The starting materials were $0.5 \mathrm{~g}$ of tantalum powder (with purity $99.9 \%$ ), $5 \mathrm{ml} \mathrm{HF}, 0.5 \mathrm{~g}$ citric acid in $75 \mathrm{ml} \mathrm{H}_{2} \mathrm{O}$ and $\mathrm{NaOH}$ for $\mathrm{pH}$ adjustment at 6.5. The mixture was introduced into Morey-type autoclave (with $37.6 \mathrm{ml}$ capacity) occupying $80 \%$ of the total volume. The mixture from autoclave was maintained at the temperature of $160^{\circ} \mathrm{C}$ (for sample A) and $200^{\circ} \mathrm{C}$ (for sample B), for $12 \mathrm{~h}$. After decantation and filtration, the resulting precipitate was washed with distilled water on a filter paper and then laid out to dry in an air oven, at $80^{\circ} \mathrm{C}$, resulting in powder samples. The sample of pure $\mathrm{NaTaO}_{3}$ (denoted by sample C) 
was synthesized by the sol-gel method using $1 \mathrm{ml}$ tantalum ethoxide and $1 \mathrm{M}$ sodium hydroxide, which was added to 1:1 alcohol-water solution. The precipitate was filtered, washed several times with bi-distilled water and dried at $100{ }^{\circ} \mathrm{C}$ for $2 \mathrm{~h}$. Then, for crystallization the sample was heat treated for $6 \mathrm{~h}$ at $600^{\circ} \mathrm{C}$, at a heating rate of $5{ }^{\circ} \mathrm{C} / \mathrm{min}$.

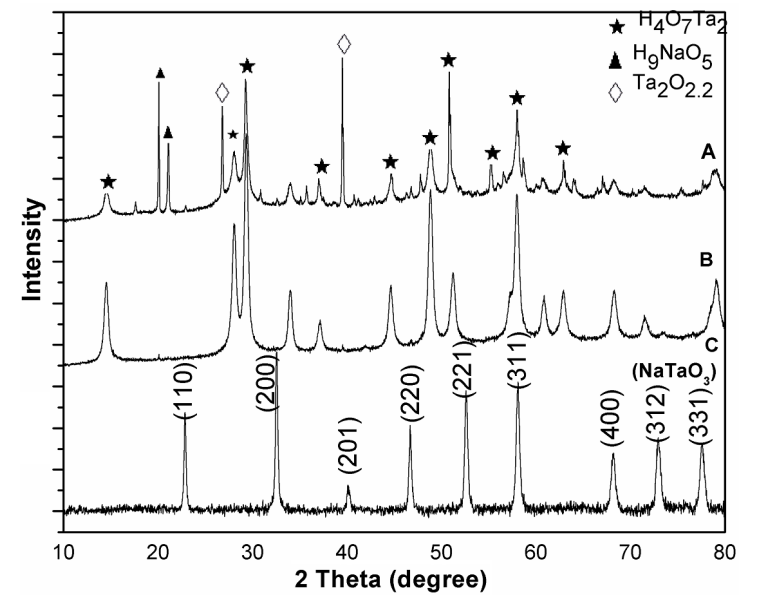

Fig. 1. XRD patterns of the samples.

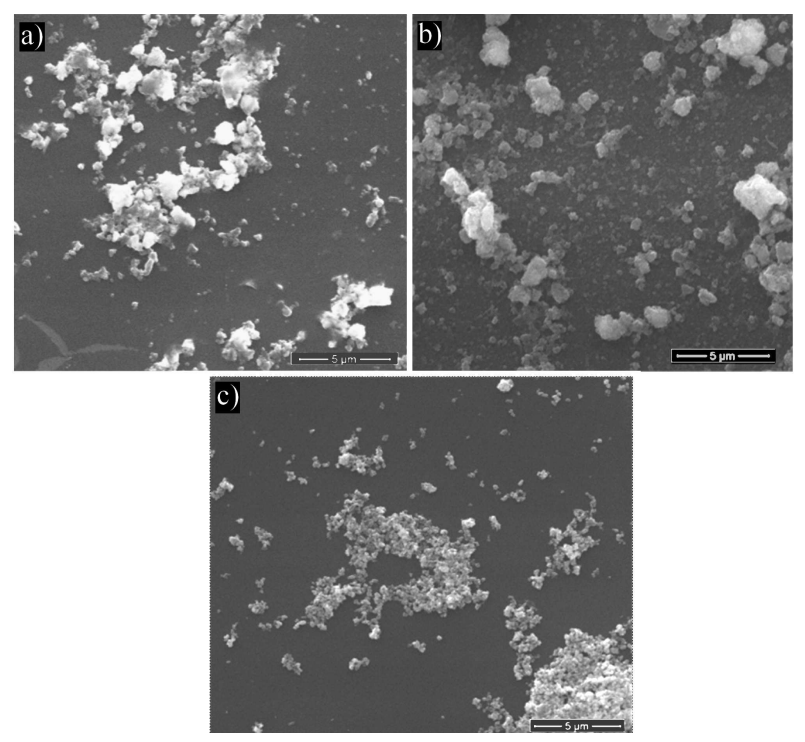

Fig. 2. SEM images of the samples: (a) sample A, (b) sample B, and (c) sample C.

The crystalline structure of the obtained samples was investigated by XRD using PANalytical - X'Pert PRO MPD diffractometer with $\mathrm{Cu}$ tube. The XRD patterns of the investigated samples are presented in Fig. 1, which shows that samples $\mathrm{A}$ and $\mathrm{B}$ consist of mixture of $\mathrm{Na}-$ Ta oxides (including $\mathrm{NaTaO}_{3}$ and other compounds such as tantalum hydrogen oxide $\mathrm{H}_{4} \mathrm{O}_{7} \mathrm{Ta}_{2}$, sodium hydroxide hydrate $\mathrm{H}_{9} \mathrm{NaO}_{5}$ and tantalum oxide $\mathrm{Ta}_{2} \mathrm{O}_{2.2}$ ), whilst sample $\mathrm{C}$ is pure $\mathrm{NaTaO}_{3}$ (according to the standard data JCPDS card No. 74-2478).

The morphology of samples was observed using a PANalytical SEM and the images are shown in Fig. 2. As can be seen in Fig. 2, samples consist of grains, connected each other in agglomerated clusters and the grain size of sample $\mathrm{C}$ is smaller than that of samples $\mathrm{A}$ and $\mathrm{B}$.

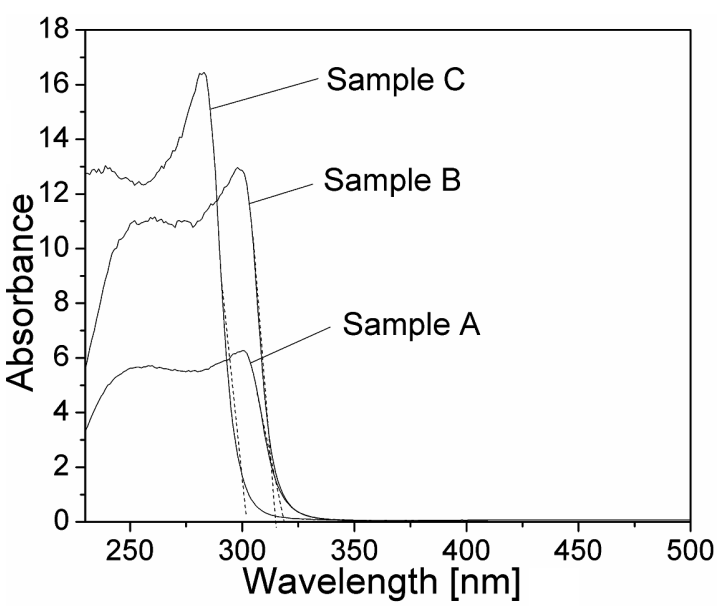

Fig. 3. UV-vis spectra of the samples.

The UV-VIS spectroscopic analysis was performed using DRUV-VIS spectrometer Lambda 950 Perkin-Elmer (within the working range $200-600 \mathrm{~nm}$ ). Figure 3 shows the absorbance spectra that were converted from reflection by the Kubelka-Munk method [8]. The wavelength at the absorption edge, $\lambda_{\mathrm{g}}$ was determined as the intercept on the wavelength axis of the tangent line, drawn on the absorption spectrum. As can be observed from Fig. 3, the wavelength at the absorption edge was $\lambda_{\mathrm{g}}=319 \mathrm{~nm}$ for sample A, $\lambda_{\mathrm{g}}=315 \mathrm{~nm}$ for sample B and $\lambda_{\mathrm{g}}=302 \mathrm{~nm}$ for sample C. The values of the band gap energy $\left(E_{\mathrm{g}}\right)$ were computed from the UV-vis spectra using the following equation [11]:

$$
E_{\mathrm{g}}(\mathrm{eV})=\frac{1240}{\lambda_{\mathrm{g}}(\mathrm{nm})}
$$

The values obtained for $E_{\mathrm{g}}$ are $3.88 \mathrm{eV}$ for sample $\mathrm{A}$, $3.93 \mathrm{eV}$ for sample $\mathrm{B}$ and $4.1 \mathrm{eV}$ for sample $\mathrm{C}$, being very close to the values reported in Ref. [11] where the onestep hydrothermal method for the obtaining of $\mathrm{NaTaO}_{3}$ has been used. In Ref. [8] values of $E_{\mathrm{g}}$ in order of 4.0 $4.1 \mathrm{eV}$ were reported for $\mathrm{NaTaO}_{3}$ obtained by sol-gel method, whilst in Ref. [12], value of $E_{\mathrm{g}}=3.8 \mathrm{eV}$ was reported for $\mathrm{NaTaO}_{3}$ obtained by the ultrasonic method.

The presence of other sodium and tantalum oxides apart from $\mathrm{NaTaO}_{3}$ leads to decrease in the band gap energy value, which may be useful for photocatalysis in that it takes place at lower frequencies than in the case of pure $\mathrm{NaTaO}_{3}$ (closer to the visible range).

\section{Results and discussion}

Electrical resistance of the samples at different temperatures, $T$ in the range $30-175^{\circ} \mathrm{C}$, was measured using a laboratory-made experimental setup. The sample was introduced into a glass tube (diameter $D=3.8 \mathrm{~mm}$ and length $L=11 \mathrm{~mm}$ ), which is placed in an electric furnace. 
The temperature of sample was measured with a thermocouple and the electrical resistance was measured with an ohmmeter. Using the measured values of the electrical resistance at various temperatures, of the length $L$ and of the diameter $D$ of the sample, the electrical resistivity, $\rho$ has been determined. Based on the experimental measurements, $\rho(T)$ dependence of samples $\mathrm{A}, \mathrm{B}$ and $\mathrm{C}$ is shown in Fig. 4.

As can be seen from Fig. 4, $\rho(T)$ dependences of samples are approximately exponential, which indicates that the samples have typical semiconductor behaviour [13].

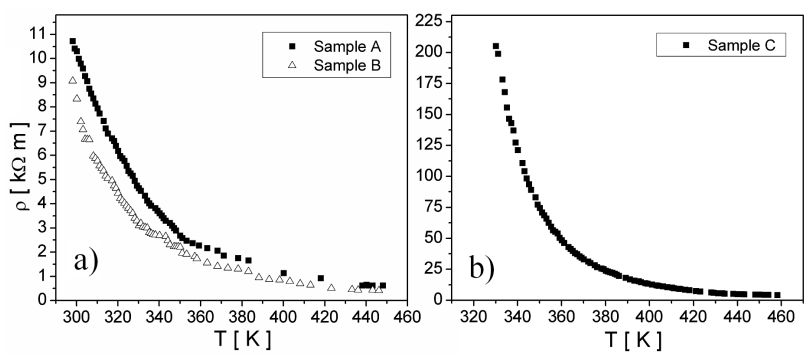

Fig. 4. The temperature dependence of the electrical resistivity of samples $\mathrm{A}, \mathrm{B}$ (part a)) and $\mathrm{C} \mathrm{b}$ ).

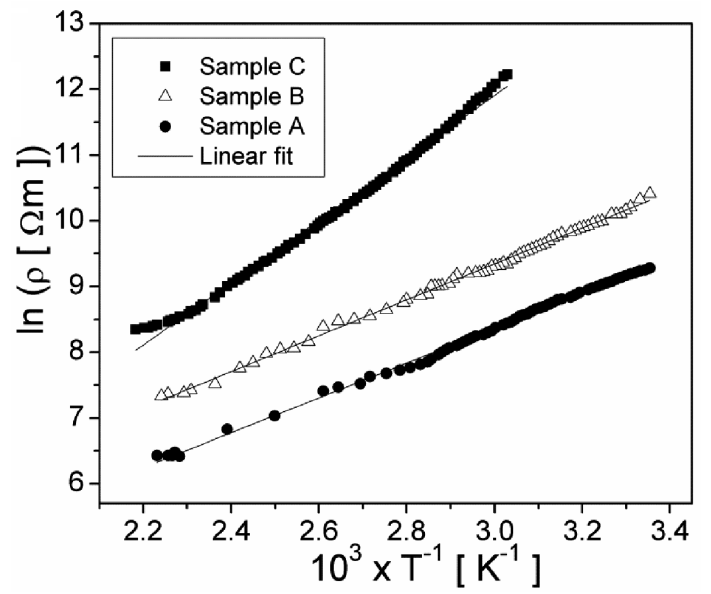

Fig. 5. The experimental dependences of $\ln \rho$ on $T^{-1}$ of the samples.

In Fig. 5 the experimental dependences of $\ln \rho$ on $T^{-1}$ of the investigated samples are shown. One can observe from Fig. 5 that these dependences are typical to semiconductor materials [13], in agreement with the equation

$$
\rho=\rho_{0} \exp \left(E_{\mathrm{a}} /(2 k T)\right) \text {. }
$$

Here, $k=1.38 \times 10^{-23} \mathrm{~J} / \mathrm{K}$ is the Boltzmann constant, $E_{\mathrm{a}}$ is the effective activation energy of the electrical conduction in the sample and $\rho_{0}$ represents the pre-exponential factor of resistivity.

The values of parameters $E_{\mathrm{a}}$ and $\rho_{0}$ were determined from the linear fit of the experimental dependence on $T^{-1}$ of $\ln \rho$. The following values were obtained: $E_{\mathrm{a}}(A)=$ $0.47 \mathrm{eV}$ and $\rho_{0}(A)=151.6 \Omega \mathrm{cm}$ for sample $\mathrm{A} ; E_{\mathrm{a}}(B)=$ $0.45 \mathrm{eV}$ and $\rho_{0}(B)=315.2 \Omega \mathrm{cm}$ for sample $\mathrm{B}$ and $E_{\mathrm{a}}(C)=0.82 \mathrm{eV}$ and $\rho_{0}(C)=9414.1 \Omega \mathrm{cm}$ for sample C.This result can be correlated to the fact that the samples $\mathrm{A}$ and $\mathrm{B}$ are mixtures of compounds $\left(\mathrm{NaTaO}_{3}\right.$, tantalum hydrogen oxide $\mathrm{H}_{4} \mathrm{O}_{7} \mathrm{Ta}_{2}$, sodium hydroxide hydrate $\mathrm{H}_{9} \mathrm{NaO}_{5}$ and tantalum oxide $\mathrm{Ta}_{2} \mathrm{O}_{2.2}$ ) whilst sample $\mathrm{C}$ has only one phase (of $\mathrm{NaTaO}_{3}$ ). The presence of hydroxyl group $(-\mathrm{OH})$ in the samples A and $\mathrm{B}$ may be responsible for the smaller values of their electrical resistivity with respect to sample $\mathrm{C}$.

The values of effective activation energy $E_{\mathrm{a}}$, obtained for the investigated samples are similar to those determined in Ref. [14] for $\mathrm{NaTaO}_{3}$ ceramic samples (i.e. $0.53 \mathrm{eV}$ at $1 \mathrm{kHz}$ ). Large values of the preexponential factor of samples, $\rho_{0}$, indicates that the electric conduction in these samples can be explained by the hopping process between localized states [15-17]. According to this model, it is assumed that the hopping process is determined by the Mott variable-range-hopping (VRH) mechanism [18]. As a result, the static conductivity, $\sigma_{\mathrm{dc}}$, is given by the following expression $[18,19]$ :

$$
\sigma_{\mathrm{dc}}=\sigma_{0} \exp \left(-\left(\frac{T_{0}}{T}\right)^{1 / 4}\right) .
$$

Here, $T_{0}$ represent the characteristic temperature [18] and is given by the equation

$$
T_{0}=\frac{\lambda \alpha^{3}}{k N\left(E_{\mathrm{F}}\right)} \text {. }
$$

In Eq. (4), $N\left(E_{\mathrm{F}}\right)$ is the density of the localized states at the Fermi level $E_{\mathrm{F}} ; \alpha \approx 10^{9} \mathrm{~m}^{-1}$ and characterizes the degree of localization and $\lambda \approx 16.6$ is a dimensionless constant [19]. Other Mott parameters, such as the hopping distance $R$ and the hopping energy $W$ are given by the following expressions [19]:

$$
\begin{aligned}
& R=\left(\frac{9}{8 \alpha k T N\left(E_{\mathrm{F}}\right)}\right)^{1 / 4}, \\
& W=\frac{3}{4 \pi R^{3} N\left(E_{\mathrm{F}}\right)} .
\end{aligned}
$$

The Mott VRH plots for the investigated samples $\left(\ln \sigma_{\mathrm{dc}}\right.$ versus $T^{-1 / 4}$ ) are presented in Fig. 6 .

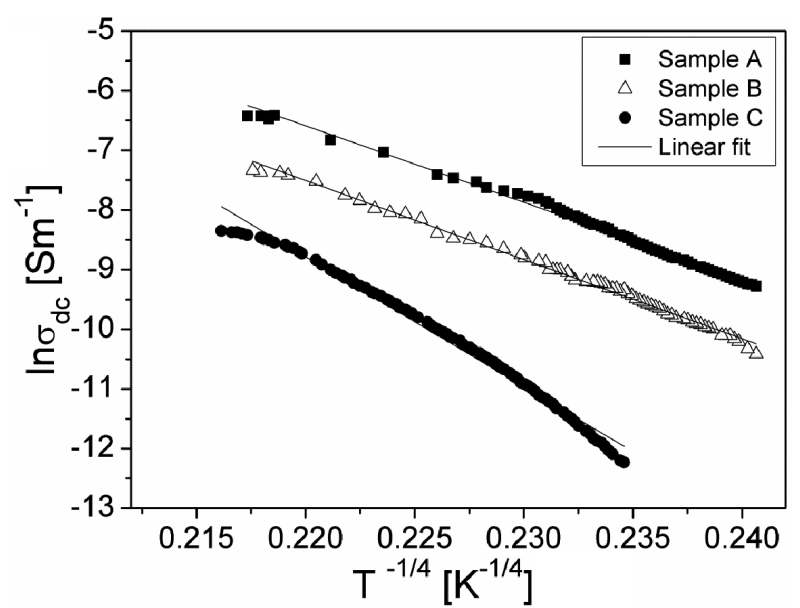

Fig. 6. Plots of $\ln \sigma$ versus $T^{-1 / 4}$ of the investigated samples. 
According to Eq. (3), by fitting the experimental dependences $\ln \sigma\left(T^{-1 / 4}\right)$ with a linear equation one obtains the parameters $T_{0}$ of samples. From Eq. (4) and using the values obtained for $T_{0}$ we have computed the density of the localized states at the Fermi level $N\left(E_{\mathrm{F}}\right)$. The values obtained for parameters $T_{0}$ and $N\left(E_{\mathrm{F}}\right)$ are shown in Table I.
From Table I it is observed that the Mott parameters obtained for the samples A and B are approximately equal. The density of localized states at the Fermi level, $N\left(E_{\mathrm{F}}\right)$ is smaller for sample $\mathrm{C}$ than for the samples A and $\mathrm{B}$, due to the fact that sample $\mathrm{C}$ consists of a single phase of pure $\mathrm{NaTaO}_{3}$.

TABLE I

Mott parameters calculated at three temperatures for the samples A, B, and C.

\begin{tabular}{c|c|c|c|c|c|c|c|c}
\hline \hline \multirow{2}{*}{ Samples } & $T_{0}$ & $N\left(E_{\mathrm{F}}\right)$ & \multicolumn{3}{|c|}{$\mathrm{R}[\mathrm{nm}]$} & \multicolumn{3}{c}{$\mathrm{W}[\mathrm{meV}]$} \\
\cline { 5 - 9 } & {$[\mathrm{K}]$} & {$\left[\mathrm{cm}^{-3} \mathrm{eV}^{-1}\right]$} & $300 \mathrm{~K}$ & $350 \mathrm{~K}$ & $440 \mathrm{~K}$ & $300 \mathrm{~K}$ & $350 \mathrm{~K}$ & $440 \mathrm{~K}$ \\
\hline $\mathrm{A}$ & $0.27 \times 10^{9}$ & $7.13 \times 10^{17}$ & 15.7 & 15.1 & 14.3 & 86 & 97 & 115 \\
$\mathrm{~B}$ & $0.31 \times 10^{9}$ & $6.21 \times 10^{17}$ & 16.3 & 15.7 & 14.8 & 89 & 100 & 119 \\
$\mathrm{C}$ & $2.25 \times 10^{9}$ & $0.855 \times 10^{17}$ & 26.7 & 25.7 & 24.2 & 147 & 164 & 197
\end{tabular}

Using the computed values of $N\left(E_{\mathrm{F}}\right)$ and Eqs. (5) and (6) we have determined the hopping distance $R$ and the hopping energy $W$ at three temperatures within the measurement range. The obtained values of $R$ and $W$ are shown in Table I. As can be observed from Table I, for all samples the hopping distance, $R$ decreases with the increase in temperature and the hopping energy, $W$ increases with the increase in temperature. The hopping distance $R$ and the hopping energy $W$ are larger for sample $\mathrm{C}$ than for the samples $\mathrm{A}$ and $\mathrm{B}$. This result can also be correlated to the fact that sample $\mathrm{C}$ has only one phase (of $\mathrm{NaTaO}_{3}$ ) whilst the samples $\mathrm{A}$ and $\mathrm{B}$ are mixtures of sodium and tantalum oxides.

Based on the results shown in Table I one can observe that the ratio of the hopping energy $W$ and the thermal energy $k T$ has values between the range of $(3-4)$ and $\alpha R$ is much larger than unity for all samples. These results are in agreement with the Mott variable-rangehopping (VRH) model [18, 19].

\section{Conclusions}

Two composite material samples of $\mathrm{Na}-\mathrm{Ta}$ oxides were synthesized by the hydrothermal method at different reaction temperatures for $12 \mathrm{~h}\left(160^{\circ} \mathrm{C}\right.$ for sample A and $200^{\circ} \mathrm{C}$ for sample B). As reference sample, another one, consisting of pure $\mathrm{NaTaO}_{3}$ has been prepared by the sol-gel method (sample C).

The samples were analyzed by XRD, SEM, UV-vis spectra and electrical measurements.

The band gap energy, $E_{\mathrm{g}}$ evaluated by UV-vis spectra measurements, was $3.88 \mathrm{eV}$ for sample A and $3.93 \mathrm{eV}$ for sample $\mathrm{B}$, very close to $E_{\mathrm{g}}$ of pure $\mathrm{NaTaO}_{3}(4.01 \mathrm{eV}$ for sample $\mathrm{C}$ ). Consequently, the samples $\mathrm{A}$ and $\mathrm{B}$ can be used in photocatalysis in a similar manner as $\mathrm{NaTaO}_{3}$.

The effective activation energy of the electrical conductivity $E_{\mathrm{a}}$ evaluated from electrical resistivity measurements, was $0.47 \mathrm{eV}$ for sample A, $0.45 \mathrm{eV}$ for sample B and $0.82 \mathrm{eV}$ for sample $\mathrm{C}$, confirming thus the typical semiconductor behaviour of samples.

In the investigated temperature range, the static conductivity mechanism in all samples was explained using Mott's VRH model. Based on this model, different related parameters were computed, such as: the characteristic temperature coefficient $T_{0}$, the localized states at the Fermi level $N\left(E_{\mathrm{F}}\right)$, the hopping distance $R$, and the hopping energy $W$.

The Mott parameters of samples A and B have approximately the same values, and are much different from those of sample C. This difference may be correlated with the composition of samples, namely the samples A and B are mixtures of $\mathrm{NaTaO}_{3}$ and $\mathrm{Na}-\mathrm{Ta}$ oxides, whilst the sample $\mathrm{C}$ is pure $\mathrm{NaTaO}_{3}$.

The experimental results showed that the photocatalytic properties of the investigated samples are not significantly affected by the presence of some sodium and tantalum oxides along with $\mathrm{NaTaO}_{3}$, but the electrical properties depend very much on the composition of samples.

\section{Acknowledgments}

This work was partially supported by the strategic grant POSDRU/159/1.5/S/134378 (2014) of the Ministry of National Education, Romania, co-financed by the European Social Fund - Investing in People, within the Sectoral Operational Programme Human Resources Development 2007-2013.

\section{References}

[1] N. Wang, C.Q. Zhang, H.C. He, Xiao Li, Jian Yang, Powder Technol. 205, 61 (2011).

[2] C.H. Feng, S.P. Ruan, J.J. Li, B. Zou, J.Y. Luo, W.Y. Chen, W. Dong, F.Q. Wu, Sens. Actuators $B$ Chem. 155, 232 (2011). 
[3] N. Setter, J. Eur. Ceram. Soc. 21, 1279 (2001).

[4] W. Wunderlich, J. Nucl. Mater. 389, 57 (2009).

[5] W. Wunderlich, S. Soga, J. Ceram. Process. Res. II, 233 (2010).

[6] X. Li, J.L. Zang, Catal. Commun. 12, 1380 (2011).

[7] D.G. Porob, P.A. Maggard, J. Solid State Chem. 179, 1727 (2006).

[8] Wan-Hsien Lin, Ching Cheng, Che-Chia Hu, Hsisheng Teng, Appl. Phys. Lett. 89, 211904 (2006).

[9] J.A. Nelson, M.J. Wagner, J. Am. Chem. Soc. 125, 332 (2003).

[10] Y. He, Y. Zhu, Chem. Lett. 33, 900 (2004).

[11] Yi-Xin Zhao, Da-Rui Liu, Fang-Fei Li, Dian-Fan Yang, Yin-Shan Jiang, Powder Technol. 214, 155 (2011).

[12] O. Vázquez-Cuchillo, A. Manzo-Robledo, R. Zanella, N. Elizondo-Villareal, A. Cruz-López, Ultrason. Sonochem. 20, 498 (2013).
[13] L. Solymar, D. Walsh, Electrical Properties of Materials, Oxford University Press, Oxford 2004.

[14] S.K. Roy, S.N. Singh, K. Kumar, K. Prasad, Adv. Mater. Res. 2, 173 (2013).

[15] K. Prasad, C.K. Suman, R.N.P. Choudhary, Adv. Appl. Ceram. 105, 258 (2006).

[16] K. Prasad, K. Amar Nath, S. Bhagat, K.P. Chandra, A.R. Kulkarni, Adv. Appl. Ceram. 109, 225 (2010).

[17] R.M. Hill, Philos. Mag. 24, 1307 (1971).

[18] N.F. Mott, E.A. Davis, Electronic Process in Nanocrystalline Materials, Clarendon, Oxford 1979.

[19] E.A. Davis, N.F. Mott, Philos. Mag. 22, 903 (1970). 